\title{
Explorações da noção de materialidade da
} comunicação'

\section{Simone Pereira de Sá}

\section{RESUMO}

O trabaiho discute a especificidade da contribuição do circulo de Hans Ulrich Gumbrecht em Stanford, focando a proposta da teoria da materialidade da comunicação e sua contribuição sobre as novas tecnologias.

Do nosso ponto de vista, esta noçāo deve ser melhor discutida, consjderando-se as contribuiçōes de autores tais como Walter Benjamin e Marshall McLuhan, entre outros.

\section{ABSTRACT}

The article discusses the specificity of Hans Ulrich Gumbrecht's group in the Stanford University, focusing on the so called "materialities of communication" theory and its contribution to the reflexion on new tchnologies.

From our point of view, this notion should be beller discussed, considering the contribution of authors as Walter Benjamin and Marshall McLuhan, among others.

\footnotetext{
I Trabalho apresentado ao NP Tecnologias da Comunicaçào, sob a coordenação de Paulo Vaz.

Simone Pereira de Sá Doutora eé professora adjunta do Departamento de Estudos Culturais e Midia da Universidade Federal Fluminense e professora do Programa de Pós. Craduaçāo em Comunicação de mesma Universidade. Coordena o CULT - Laboratorio de Pesquisas em Cultura Urbana, Lazer e Tecnologias da Comunicąão, onde desenvolve pesquisa sobre as novas tecnologiase música eletrônica (CNPq $2004 /$ 2007).
} 


\section{I - Introdução}

I don't explain; I explore! Marshall Mc Luhan

Em artigo publicado na revista eletrônica Ciberlegenda, no ano de 2001, Erick Felinto apresenta alguns pressupostos da "teoria das materialidades", chamando-nos a atenção para as possibilidades dos estudos conduzidos sob a liderança de Hans Ulrich Gumbrecht na Universidade de Stanford, especialmente nas suas aplicações em torno das chamadas novas tecnologias da comunicação.

Conforme observa Felinto, não se trata de sugerir uma epistemologia absolutamente nova, mas de encarar de maneira renovada uma noção bastante tradicional. Desta forma, na sua tentativa de tradução do termo, cabe assinalar que:

falar em "materialidades da comunicação" significa ter em mente que todo ato de comunicação exige a presença de um suporte material para efetivar-se. Que os atos comunicacionais envolvam necessariamente a intervenção de materialidades, significantes ou meios pode parecer-nos uma idéia já tão assentada e natural que indigna de menção. Mas é precisamente essa naturalidade que acaba por ocultar diversos aspectos e conseqüências importantes das materialidades na comunicação - tais como a idéia de que a materialidade do meio de transmissão influencia $e$ até certo ponto determina a estruturação da mensagem comunicacional.

Este artigo captou meu interesse imediato, por remeter-se a uma perspectiva com a qual eu trabalhava naquele momento em um curso: a assim chamada Escola de Toronto.

Conforme sabemos, a contribuição mais relevante de autores como McLuhan (1973), Harold Innis (1950; 1951), R.Logan (2000) e E. Havelock (1998) aos estudos da comunicação é justamente a que também Felinto enfatiza na Teoria das Materialidades: a de considerar as diferentes tecnologias da comunicação, para além dos conteúdos que transmitem, como determinantes da própria "forma de pensar" de uma cultura, distinguindo-se assim os efeitos da oralidade, da escrita, do advento da eletricidade, da cultura informacional.

Passados quatro anos, Felinto reapresenta o argumento sobre a importância da Teoria das Materialidades, que passou de certa forma despercebido entre nós, em seu artigo para o GT de Tecnologias da Informação e da Comunicação da COMPÓS de 2004. Novamente, estou às voltas com as mesmas questões, agora por conta de pesquisa sobre a música eletrônica no Brasil e sua experiência estética ${ }^{3}$. 
Este artigo é fruto das indagações produzidas no intervalo que separa este duplo encontro com os textos de Erick e de algumas perplexidades frente a suas proposições. Nele, pretendo discutir a especificidade da contribuição da Teoria da Materialidade para os estudos de comunicação, especialmente ao lidar com as novas tecnologias.

Pois, ainda que o autor seja cuidadoso o bastante para reconhecer que não se trata de uma "epistemologia absolutamente nova", suas sugestões são as de que encontraríamos nestes estudos do Departamento de Literatura Comparada de Stanford uma forma renovada de encarar a questão da materialidade.

Minha proposta é de um deslocamento sutil: sem dúvida, não caberia aqui desmerecer as contribuições de Gumbrecht e seu círculo, mas sim a de perceber que eles apropriam-se - para fins de um debate dentro do campo dos estudos literários - de argumentos que podem ser enquadrados dentro de uma tradição que tem sido sistematicamente explorada na discussão sobre o impacto das tecnologias dentro dos estudos de comunicação.

Sem qualquer preconceito contra a interdisciplinaridade, parece-me que, neste caso, torna-se obrigatório o reconhecimento dos limites de cada um dos campos e de seus interlocutores - no caso o da comunicação e o dos estudos literários. E se o impacto das premissas da teoria da materialidade é realmente o de um "olhar renovado" na interlocuçào com o campo da literatura - que até final dos anos 60 privilegia a análise semântica - de conteúdo e do sentido de um texto, tomando este último como uma abstração natural e ahistórica que coincide com a forma livro; a tradição dos estudos sobre as tecnologias, dentro da comunicação é outra, considerando "desde o início" da modernidade o impacto material dos meios de comunicação.

Buscando desenvolver este argumento nas próximas páginas, procuro identificar uma linhagem de pensadores que se debruçam sobre a temática da materialidade da comunicação - leia-se da importância dos suportes materiais tanto quanto sobre a ampla gama de relações entre corpo e as tecnologias da comunicação. As idéias aqui apresentadas estão longe de formarem uma Teoria ou Escola unificada. Distante de qualquer idéia totalizante, apresento uma paidéia de autores, com pontos de vista distintos em torno do tema que vão desde os clássicos argumentos de Walter Benjamin, passando pelas contribuiçào da historiografia, da corrente pragmatista e da noção de atividade ergódica de Aarseth.

Entretanto, vistos em conjunto, os autores desta pequena genealogia permitem a afirmação de que a ênfase na materialidade é antes um dos leitmotifs da discussão do campo comunicacional e, definitivamente, não pode ser creditada ao círculo de Gumbrecht em Stanford. O que não invalida, de maneira nenhuma, o esforço reflexivo destes últimos, mas contextualiza a sua reflexão . 
Vale insistir que não se trata aqui de uma discussão em torno das origens de uma idéia, do momento inaugural de uma perspectiva ou do pioneirismo de alguns autores mas do refinamento do debate a partir da compreensão da especificidade do ponto de vista apresentado pela teoria das Materialidades e da rentabilidade epistemológica efetiva de seus conceitos na reflexão sobre as tecnologias da comunicação.

Ao mesmo tempo - e en passant - trata-se de uma reflexão sobre os limites da interdisciplinaridade. Pois, se não tenho a menor dúvida de que as apropriações que fazemos, dentro da comunicação, do pensamento de diferentes disciplinas - filosofia, história, ciências sociais, psicologia, estudos literários - são absolutamente legitimas e mesmo fundadoras de nossa forma de operar, creio que a discussão sobre os desafios epistemológicos de cada campo e operacionalidade de noções transpostas de um campo a outro também permanece como legitima, mesmo em tempos de crise das noções de totalização, temporalização e representação, conforme sublinha Gumbrecht. (1998a; 1998b)

\section{II - Ampliando a noção de materialidade}

"Estes teóricos centraram-se no que podemos chamar concepção neurológica de modernidade. Eles afirmavam que a modernidade também tem que ser entendida como um registro da experiência subjetiva fundamentalmente distinto, caracterizado pelos choques fisicos e perceptivos do ambiente urbano moderno. (...) A modernidade implicou um mundo fenomenal - especificamente urbano - que era marcadamente mais rápido, caótico, fragmentado e desorientador do que as fases anteriores da cultura humana. Em meio à turbulência sem precedentes do tráfego, barulho, painéis, sinais de trânsito, multidões que se acotovelam, vitrines e anúncios da cidade grande, o individuo defrontou-se com uma nova intensidade de estimulação sensorial. A metrópole sujeitou o individuo a um bombardeio de impressões, choques e sobressaltos. O ritmo de vida também se tornou mais frenético, acelerado pelas novas formas de transporte rápido, pelos horários prementes do capitalismo moderno e pela velocidade sempre acelerada da linha de montagem". (Singer; 2001; 116)

A citação acima, que se refere ao conjunto das obras de Benjamin, Simmel e Kracauer, sintetiza meu ponto de partida. Tematizando a ampla gama de novas relações entre corpo e tecnologias da comunicação; e explorando a dimensão sensorial e cognitiva destes fenômenos, os autores produzem observações seminais sobre o que Gumbrecht vai chamar de "modernização dos sentidos." (1998ª) 
comercial de larga escala", Shusteman cita o rock - e detém-se no funk e no rap americanos para contestar seus opositores.

Discutindo o aspecto "somático" destas expressões musicais - que é o que cabe sublinhar, ele primeiramente reproduz o conhecido argumento de Adomo e Horkheimer, segundo o qual "a música pop é regressiva, inválida do ponto de vista estético, por constituir-se um estímulo somático que não exige do espectador nenhum tipo de esforço intelectual. "Toda conexão lógica que implique esforço mental é escrupulosamente evitada" resumem os autores, na crítica clássica da Dialética do Esclarecimento.

A seguir, Shusterman contra-argumenta sobre a quantidade de energia, de esforço corporal requisitado da audiência num espetáculo de rock, por exemplo, desenvolvendo um longo argumento que pode ser sintetizado no seguinte parágrafo: "Desta forma, as artes populares, assim como o rock, sugerem uma estética radicalmente revisada, com um retorno alegre e impetuoso da dimensão somática, que a filosofia reprimiu, por tanto tempo, a fim de preservar sua própria hegemonia (pela supremacia do intelecto) em todos os campos de valores humanos. Não é de se surpreender que a legitimidade estética de tal arte seja negada com veemência e que seus esforços corporais sejam ignorados ou rejeitados com esforço inacional enn relação à verdadeira finalidade da arte - a finalidade intelectual. O fato de esta arte e sua apreciação ter raizes numa civilização não ocidental as tonna ainda mais retrógradas e inaceitáveis.'(1998; 119).

Segue-se uma análise detida do autor sobre o funk e o rap, que são exemplares de sua proposta, que é a de compreender estas expressões estéticas como legítimas, em seus próprios termos - onde o estímulo sensorial é sem dúvida uma das características. Análise que merece aprofundamento e que reduzirei a esta menção, a fim de que possa ainda trazer ao diálogo uma outra tradição muito fortemente ligada à materialidade da comunicação.

Tratam-se de autores que, longe de compartilharem uma mesma perspectiva, têm em comum o interesse pela escrita, pela imprensa e pelas fomas de leitura no Ocidente, remetendo-se a gestos, espaços e hábitos ou para as circunstâncias de apropriaçĩo, onde poderíamos citar rapidamente Paul Zumthor (2003), Roger Chatier (1997), Elixibeth Eisenstein (1998)-dentre outros. 11

Ainda que não possam ser visto em conjunto como compartilhando uma mesma perspectiva teórico-metodológica, todos eles enfatizam a premissa de que a escrita -e pode-se dizer que todas as práticas de armazenamento e transmissão da informação têm uma história material cuja consideração é crucial. Longe de uma operação intelectual abstrata - e instaurada no Ocidente de uma vez por todas - eles interessam-se pelos diferentes suportes de leitura, as diferentes maneiras de ler, o uso do corpo, a inscrição desta(s) prática(s) dentro de um espaço, a relação consigo ou com outro na leitura cm silêncio ou em $\mathrm{VOZ}$ alta produzindo ritmos distintos, interessando-lhes sempre as circunstâncias materiais em que oconre esta atividade.

Ancorados em fortes evidências, enfatizam ainda a necessidade de se pensar em toda uma série de clivagens culturais para além da grande divisão entre alfabetizados e analfabetos, obrigando-nos a reconhecer os limites da perspectiva da Escola de 
Toronto em torno dos efeitos de diferentes tecnologias e justificando a observação de Martin-Barbero (2001) de que: "Ainda está por se fazer uma história social da leitura que incorpore a história dos modos de ler a uma tipologia dos públicos leitores e das mediações que têm permitido a passagem de uns a outros."

Estes estudiosos renovam a discussão sobre o impacto da imprensa no Ocidente, abrindo um leque de questões cuja rentabilidade epistemológica ultrapassa em muito o campo dos estudos medievalistas, atingindo os estudos literários e a comunicação.

Aqui, parece-me que caberia ainda mencionar uma última referência, fora deste campo da história social, que também ilumina aspectos da discussão sobre a materialidade da comunicação. Trata-se do trabalho de Espen Aarseth (1997), especialmente de suas noções de cibertexto e de literatura ergódica. Pois, na definição do autor, a noção de literatura ergódica remete-se claramente ao texto que admite algum tipo de feedback, e assim demanda do "leitor" um "esforço não trivial", somático, físico, distinto daquele esforço interpretativo dos livros, que é objeto dos estudos literários e que supõe uma retirada do corpo do processo de leitura.

Seus exemplos são diversos: I-Ching, MUDs, jogos de computador, alguns experimentos literários das vanguardas tais como os poemas de Apolinaire ou livros de Julio Cortázar. Todos eles vistos em conjunto como pertencentes a uma categoria ampla - chamada de cibertextos - que têm por característica a demanda de esforço físico, performativo do leitor para "atravessá-los".

Aqui, os (ciber) textos são pensados como máquinas literárias e os leitores como jogadores, que devem explorar esta máquina textual, descobrir seus caminhos secretos, 40 perder-se nos labirintos.

O exemplo mais óbvio é o de um jogo de computador, um game. Ali, frente a um emaranhado de informações textuais, a batalha do jogador não é somente a batalha semiótica, da interpretação, mas sim o desafio de seguir adiante, de ultrapassar as barreiras propostas pelo jogo e intervir na história. Trata-se portanto de um prazer textual distinto daquele do leitor de literatura.

Finalmente, a própria noção de texto precisa ser redefinida para englobar estes exemplos acima mencionados, uma vez que o moderno conceito de texto advindo dos estudos literários parece ainda avaliar estas experiências textuais com as categorias tradicionais; e claro, negando qualidades "literárias" aos novos experimentos.

\section{III - Considerações finais}

Voltemos agora à teoria das materialidades. Dado o espaço exíguo para desenvolver os argumentos, gostaria de remeter o leitor à excelente apresentação dos seus pressupostos realizada por Felinto no texto mencionado da Ciberlegenda; além da Introdução de Rocha ao livro Corpo e Forma.(1998;b).

Dentro destas premissas, caberia destacar a proposta de uma crítica póshermenêutica de Gumbrecht que ganha maior sistematização a partir de sua chegada em Stanford no final dos anos 80. Segundo o autor, a necessidade de ultrapassar o 
campo hermenêutico que caracteriza a modernidade - dominado pelas noções de verdade, interioridade, sentido, sujeito e espirito numa longa história que passa por Descartes, Dilthey e Heidegger - advém das crises enfrentadas na contemporaneidade. Crises que podem ser traduzidas pela noção de pósmodernidade, remetendo a um novo ambiente epistemológico marcado pelas categorias de destemporalização - como colapso do tempo linear que flui do passado para o presente, em prol de um presente estendido; destotalização - como a crise das meta-narrativas; e desreferencialização - como o movimento que questiona a estabilidade das relações do sujeito com o mundo.

Opondo-se portanto ao paradigma hermenêutico - cujos parâmetros são o par interpretação/ expressão e cuja premissa básica é a de ultrapassar a superfície dos fenêmenos e buscar "uma dimensão que permita o resgate da plenitude da interioridade espiritual"; Gumbrecht desenvolve os princípios para um campo nãohermenêutico, onde a busca pelo sentido, traço marcante da interpretação, substituise pela indagação sobre como os sentidos constituem-se.

E para tanto, o autor propõe perceber a forma e o conteúdo dos meios de comunicação como dois eixos de análise autônomos, ainda que articulados, considerando portanto a "possibilidade de tematizar o significante sem necessariamente associá-lo ao significado". Eixos que ainda podem subdividir-se, a partir da utilização conceitual de Hjelmslev entre forma da expressão e substância da expressão (significante) - e forma do conteúdo e substância do conteúdo, (significado) num "quadrilátero conceitual" onde cada termo pode ser analisado isoladamente.

Além disto. com uma clara inspiração mcluhaniana, ele propõe compreender as formas de acoplagem estrutural destes diferentes sistemas - ou seja a forma como um novo sistema emerge da relação do meu corpo com o computador, por exemplo, formando novas cadeias de significantes onde a noção de ritmo é fundamental.

Completando a proposta, temos as proposições de Kittler que diz: "a comunicação é encarada menos como uma troca de significados, de idéias sobre [algo] e mais como uma performance posta em movimento por vários significantes materializados. Trata-se assim de uma empresa essencialmente preocupada com as potencialidades e pressões de estilização que reside em técnicas, tecnologias, materiais, procedimentos e meios." (cit in Felinto; 2001).

Numa área - a dos estudos literários - que até o final dos anos 70 associa a "cultura do livro" à alfabetização, sobre a importância da máquina de escrever para o pensamento de Nietzsche. Tratam-se de abordagens sugestivas, que dialogam com referências variadas, onde são recorrentes as menções a Benjamin, McLuhan, Zumthor, Foucault, Derrida e Luhmann - que também aparecem nos trabalhos solitários de Gumbrecht.

Mas, à medida que se avança na leitura destes trabalhos, toma-se mais dificil responder à indagação sobre qual é efetivamente a contribuição epistemológica da 
Teoria das Materialidades para a discussão da comunicação, especialmente no que diz respeito às novas tecnologias.

Primeiramente porque nunca tivemos uma tradição hermenêutica tão consolidada no campo comunicacional - salvo, talvez nos estudos cinematográficos. Desta forma, a discussão sobre os impactos ou efeitos da tecnologias sempre predominou como pauta para nossas reflexões, a ponto de Umberto Eco identificar o par apocalíticos/integrados como chave para este contexto.

Em segundo lugar porque os autores que compõem o leque de referências do grupo de Stanford, especialmente Benjamin e McLuhan - têm presença efetiva e prolongada nos estudos da comunicação. Nem mesmo o crédito de uma "leitura renovada" sobre os autores pode ser atribuída aos colaboradores da coletânea, que tratam antes de explorar e corroborar premissas anteriores.enunciação quanto da materialidade do suporte do meio de comunicação."(cf: Rocha; in: Gumbrecht; 1998b; 47).

Dentro deste campo de indagações as possibilidades de diálogo são inúmeras. Mas, para tanto, trata-se de reconhecer que também inúmeras e persistentes são as abordagens sobre a materialidade da comunicação, tornando descabida a referência a um grupo como porta-voz desta perspectiva. Antes, creio que ela torna-se mais produtiva se pensada como um olhar que permeia parte de estimulantes estudos do campo da comunicação desde há muito.

De uma teoria ligada ao grupo de Gumbrecht em Stanford a um olhar ampliado - trata-se, sem dúvida, de um deslocamento muito sutil dos parâmetros da discussão.

42 Mas, em tempos de crise dos grandes enunciados, me parece que almejar ao refinamento do debate a partir do ajuste microscópico de nossas lentes é um objetivo defensável.

\section{Bibliografia}

AARSETH, Espen-Cybertext-Perspectives on Ergodic Literature. Baltimore and Lndon, The John Hopkins Univ. Press, 1997

BAUGH, Bruce - "Prolegômenos a uma estética do Rock". Novos Estudos CEBRAP, 38, março 1994

BAUMAN, Zygmunt - Comunidade: a busca por segurança no mundo atual. Rio de Janeiro, Ed. Jorge Zahar, 2003

BENJAMIN, Walter - Obras Escolhidas. Magia e Técnica, Arte e Politica. São Paulo, Brasiliense, 1994.(Obras Escolhidas, v.1)

CAVALLO \& CHARTIER - História da leitura no mundo ocidental. SP, Ática, 1998

CHARTIER, Roger - A ordem dos livros. Lisboa; Veja, Passagens. 1997. DEWEY, John - "Art as experience". In: Late works of John Dewey, Carbondale, Southern Illinois University Press, 1987, vol 10

EISENSTEIN, Elisabeth -A Revolução da cultura impressa no Ocidente. Os primórdios da Europa Moderna. SP, Ed Ática, 1998 
FELINTO, Erick - "Materialidades da Comunicação: Por um novo Lugar da Matéria na teoria da Comunicação". Revista Eletrônica Ciberlegenda, n. 5 , 2001

- "O corpo impuro: sobre a digitalização da matéria no imaginário da cibercultura". CD-ROM da COMPÓS. Universidade Metodista, São Bernardo do Campo, 2004

FRITH, Simon et al (ed) - Sound and Vision: the music video reader.

New York, Rouletdge, 1993

GUMBRECHT, Hans Ulrich - A Modernização dos Sentidos. São Paulo, Ed. 34,1998 (a)

- Corpo e Forma. Ensaios para uma crítica não-hermenêutica.

Org: João Cesar de Castro Rocha. Rio de Janeiro, EDUERJ, 1998 (b) - \& PFEIFFER, Ludwig - Materialities of

Communication. Stanford. Stanford Univ Press, 1994

HAVELOCK, Eric - Prefácio a Platão. SP, Unesp, 1998.

INNIS, H. - The Bias of Communication. Toronto, Canadá. Univ. of Toronto Press, 1951.

- Empire and Communications. Londres, Oxford Univ. Press, 1950 LOGAN, Robert K. - The Sixth Language - Learning a Living in the Internet Age. Toronto:Stoddart Publishing Co. Limited, 2000.

LOPES, Denilson - "Experiência e Escritura". In: O Homem que amava os rapazes e outros ensaios. Rio de Janeiro. Aeroplano, 2002.

MARTIN-BARBERO, Jesús - Dos meios às mediaçōes. Comunicação, Cullura e Hegemonia. Ed. UFRJ, Rio de Janeiro, 2001

$\mathrm{MC}$ Luhan - Os meios de comunicação como extensões do homem. SP, Ed, Cultrix, 1973.

\footnotetext{
Notas

2 Este curso foi co-ministrado na UFF em parceria com Vinicius Andrade Percira, a quem agradeço pela interlocuçào e pelo acesso à bibliografia sobre a Escola de Toronto aqui mencionada c especialmente sobre a Teoria da Materialidade. Além disto seus insights sobre o tcma, generosamente compartilhados; e nossos debates, inspiram muitas das indagações deste texto. 3 Trata-se da pesquisa desenvolvida dentro da linha de pesquisa Tecnologias da Comunicação, do Programa de Pós-graduação em Comunicação da UFF, intitulada: "Música cletrônica, Tecnologias da Comunicação c Dinâmicas Identitárias." A cquipe da pesquisa ć constituída por Leonardo de Marchi, mestrando c Roberto Jorge Cameiro de Souza Leão c Marcelo Garson, alunos do curso de jomalismo e cinema da Universidade Federal Fluminense $\mathrm{UFF}$, que conta com o auxilio do CNPq.

4 Walter Benjamin, no célebre ensaio "Paris do Segundo Império" (In: Waltcr Benjamin Obras Escolhidas III) refere-se, com certa ironia à atividade do flâneur, cnquanto descendendo dos fisiologistas - escritores, estes, de um tipo de literatura tipicamente "pequeno-burguesa" que floresce $\mathrm{cm}$ Paris por volta de 1840, feita para ser "vendida nas feiras" c que se ocupa da descrição de tipos das ruas da cidade. Mesmo tecendo comentários críticos ao gênero, que segundo ele tentava familiarizar os habitantes da cidade com a inquietação frente a situações
} 
novas e estranhas com que se deparavam na metrópole, ele aponta o fundamental da flânerie. Trata-se, justamente, de fornecer o que ele chama de "fantasmagoria" (ver nota $p$. 62) - mas que chamariamos de imaginário da cidade, contribuindo, assim, para dotar os seus contemporâneos de uma consciência de si enquanto modernos. Mas, aqui, vale ainda deternos na sua distinção fundamental entre os fisiologistas - que fazem um tipo de "botânica do asfalto" descrevendo os tipos da cidade de forma amistosa, tornando-os familiares aos leitores/habitantes; e o flâneur de estirpe baudelairiana, que vai explorar antes o choque, as contradições e ambigüidades deste novo ambiente.

5 Apud in Benjamin, op. cit, p. 37.

${ }^{6}$ Ver: Baudelaire, C., As multidões (In :O Spleen de Paris, pequenos poemas em prosa. RJ, Imago, 1995 pp. 41-42), poema que traduz este sentimentos de forma exemplar: Não é dado a qualquer um mergulhar na multidão: tal desfrute é uma arte, e só faz, às expensas do gênero humano, este lauto banquete de vitalidade quem desde o berço recebeu de uma fada o gosto do disfarce e da máscara, o ódio do domicílio e a paixão da viagem.

7 A ambigüidade do flâneur pode ser marcada pela atitude de distância/mergulho presente neste gesto - o flanador desposa a multidão mas mantém sua solidão. Imerso no turbilhão da cidade, ele vai ser encontrado perdido em devaneios. Conforme Benjamin (Cf:A Paris do Segundo Império), ele antes de tudo realiza "estudos" e procura coisa diferente do homem comum. Neste mergulho ele revisita o passadoe registra o choque frente às forças damodemidade. ${ }^{8} \mathrm{Na}$ análise deste poema de As Flores do Mal, Benjamin destaça um ponto crucial desta experiência da modernidade: a visão de um "efềmera beldade" que o poeta teria amado, ao mesmo tempo que lhe é "roubada" pela multidão, também lhe é oferecida pela própria multidão.(op. cit, p.118)

${ }^{9}$ Cabe distinguir esta perspectiva da corrente que pensa estas transformações a partir da 44 ótica do poder - tal como Jonathan Crary - entre outros.

${ }^{10}$ Bauman (2003) usa este termo pejorativamente para definir as comunidades criadas em torno das práticas de consumo da indústria cultural. Proponho a utilização do termo sem o caráter pejorativo mas sim reconhecendo uma nova forma de criação de identidades.

${ }^{11}$ Não cabe nos limites deste trabalho sublinhar as divergências teóricas metodológicas que são muitas - dos autores mencionados especialmente em torno da questão do determinismo tecnológico.

\section{Palavras-chave}

1. Materialidade da comunicação

2. Tecnologias da comunicação

3. Hans Ulrich Gumbrecht

4. Marshall McLuhan

5. Walter Benjamin 